\title{
Direct to Consumer Advertising and Prescription Choice*
}

\author{
Toshiaki Iizuka $^{\dagger}$ \\ Ginger Zhe Jin ${ }^{\ddagger}$
}

\begin{abstract}
This paper examines the effect of direct-to-consumer advertising (DTCA) on doctor choice of prescription drugs. Using antihistamines as an example, we show that DTCA has a small and insignificant effect on the choice of brand despite the massive DTCA expenditure incurred in this class. In contrast, direct-to-physician advertising (i.e., detailing and medical journal advertising) has a larger and long-lasting effect on prescription choice. These results, together with the market expanding results shown in Iizuka and Jin (2005), support the view that DTCA is effective in increasing the number of outpatient visits per therapeutic class but has little impact on the choice of prescription once the patient arrives at the physician office. As a result, DTCA may be viewed as a public good for all drugs in the same class.
\end{abstract}

\section{Introduction}

Traditionally, prescription drugs were marketed towards doctors, and direct-to-consumer advertising (DTCA) was limited. This is partly because DTCA on TV was prohibitively expensive: prior to 1997, any DTCA that contained both brand name and medical claims must disclose a "brief summary" of drug effectiveness, side effects, and contraindications. As a result, TV ads with these details were long and costly. In August 1997, the Food and Drug Administration (FDA) clarified that pharmaceutical firms can advertise brand name and indications on TV

\footnotetext{
${ }^{* \dagger}$ Graduate School of International Management, Aoyama Gakuin University. Email: toshi.iizuka@gmail.com ${ }^{\ddagger}$ Department of Economics, University of Maryland \& NBER. Email: jin@econ.umd.edu. We wish to thank Thomas Hubbard, Scott Stern, Timothy Hannan, Judy Hellerstein, Bill Evans, Seth Sanders, John Rust, Robert Maness, and the participants at the NBER 2003 IO meeting for constructive comments and suggestions. Also thank Kathryn Aikon for helping us interpret the FDA rules, and Catherine Burt for guiding our usage of the NAMCS data. We acknowledge financial support from Grants-in-Aid for Scientific Research, Japan Society of Promotion of Science, and University of Maryland. All errors remain ours.
} 
without a "brief summary." ${ }^{1}$ Following the clarification, DTCA expenditures increased substantially from $\$ 800$ million in 1996 to $\$ 2.5$ billion in 2000 , which created an intensive debate on the effects of DTCA. Proponents of DTCA emphasize the educational value of DTCA: many chronic diseases are under-diagnosed and under-treated, and DTCA can inform potential patients of the existence of such medical treatment. Opponents argue, however, DTCA may mislead patients into demanding heavily-advertised drugs, leading to inappropriate drug use and unnecessary purchase of expensive drugs. ${ }^{2}$

To understand the effects of DTCA on pharmaceutical demand, it is useful to consider the impact of DTCA in two steps. In the first step, DTCA may inform the public of the existence of the medication and thereby bring potential patients to the doctor. If true, DTCA expands the prescription drug market. Second, after the patient visits the doctor, DTCA may affect the doctor's prescription choice. For example, a patient who watched a TV commercial of a prescription drug may persuade the doctor to prescribe the medicine, even if it is not the appropriate one. Clearly, proponents of DTCA stress the potential benefit from the first step, and opponents of DTCA are concerned about the harm generated by the second step.

Our previous study (Iizuka and Jin, 2005) examined the first step by combining 1994 2000 drug-specific DTCA data with the 1995 - 2000 National Ambulatory Medical Care Surveys (NAMCS) and found that higher DTCA expenditures were associated with increased doctor visits. This paper contributes to the debate by examining the second step, i.e., whether DTCA affects physician prescription choice once the patient visits a doctor. We focus on the prescription of non-sedating antihistamines, one of the most heavily DTC-advertised classes. Utilizing the data above, we estimate a discrete choice model. We allow advertising to last long and estimate depreciation rates for the four types of promotional expenditures - detailing, medical journal advertising, free samples, and DTCA (the first three target doctors). We find that DTCA has a positive but insignificant effect on specific brand choices. In contrast, advertising directed to physicians has a much larger and long-lasting effect on the choice of prescription. Thus, the primary role of DTCA appears to bring potential patients to the doctor but not to affect the choice of prescription. Overall, these results support the proponents' view that DTCA expands the aggregate demand per therapeutic class but does not distort prescription choice once the patient arrives at the physician office.

This paper contributes to the small, but growing literature that analyzes the demand effects of DTCA. ${ }^{3}$ Most of the existing evidence is based on aggregate data. Calfee et al. (2002)

\footnotetext{
${ }^{1}$ DTCA still needs to include a "major statement" of the most important risks and refer consumers to other sources for more comprehensive information.

${ }^{2}$ Both sides of the debate are well documented. See Holmer (1999) and Holmer (2002) for a summary of the proponent's position, and Hollon (1999) and Wolfe (2002) for a summary of the opponent's position.

${ }^{3}$ Even a smaller collection of literature exists on the supply side of DTCA. This includes Rosenthal et al.
} 
didn't find a significant effect of DTCA on new Statin prescriptions or renewals. Rosenthal et al. (2003) examined the aggregate sales data of five therapeutic classes and found that DTCA has a significant effect on total class sales but not on market shares within each class. Narayanan et al. (2004) examined the effect of DTCA and other marketing efforts on allergy prescriptions. They found that DTCA increases both category sales and brand share, but the latter effect is weaker than that of detailing. While closely related, our paper is different from the above references because we use patient-level prescription data rather than aggregated market-level data. The advantage of individual data is that we can control for various patient-doctor attributes such as age, gender, race, insurance status, and physician specialty. Consumer and doctor heterogeneity could drive the effect of advertising on aggregate market shares, but it is difficult for an analysis using aggregated data to control for such heterogeneity.

A working paper by Wosinska (2002) is probably the closest to ours. Using individual claim data from Blue Cross of California, she examined the impact of DTCA on the prescriptions of cholesterol-reducing drugs. She found that DTCA has a small but significant impact on the demand if the brand is on the formulary. Aside from examining a different therapeutic class, this paper is different from Wosinska's in two ways: first, we use national representative data and control for various patient and doctor characteristics, which is difficult to achieve by using claim data from a single insurer. More importantly, we allow four types of promotional expenditures to depreciate over time and estimate a separate depreciation rate for each. By this, we can distinguish the instant impact of advertising from the effect that lasts over time.

\section{Data}

We combine individual-level data from NAMCS and brand-level advertising data for nonsedating antihistamines from TNS Media Intelligence/ Competitive Media Reporting (CMR) and IMS Health. NAMCS provides a national representative sample of individual visits to office-based physicians. For each office visit, it includes the month of visit, patient demographics, insurance status, physician specialty, and prescription choices, if any. ${ }^{4}$ Monthly DTCA expenditure data from 1994 to 2001 is obtained from CMR. CMR monitors advertising expenditures in several media, including network TV, cable TV, newspapers, and magazines. In addition to DTCA, pharmaceutical firms promote their drugs via professional channels targeting physicians. This includes detailing, medical journal advertising, and free samples. From IMS Health, we obtain monthly data from July 1997 to December 2001 and annual data from 1994 to 1997. Our analysis focus on the visits that occurred between July 1997 and December 2001, but we use prior advertising data to construct advertising stock (see Section 3 for more detail).

(2002) and Iizuka (2004).

${ }^{4}$ See Cherry et al. (2001) for more detailed description of NAMCS. 
Since NAMCS doesn't collect information on prescription copays, we obtain corresponding monthly wholesale price from IMS Health. We compute patient-day price based on the sales dollars and quantity sold for each drug. We note that the wholesale price is not ideal since this may poorly correlate with the patient's copay, but this is the best we can do for a national representative sample. Aware of this caveat, we use the wholesale price as a proxy control and do not interpret its impact as price elasticity. All data are matched by drug names and by the month of visit.

The drug class we examine is the non-sedating antihistamines. We focus our attention to the second-generation non-sedating antihistamines, i.e., Claritin, Zyrtec, and Allegra. Neither generic nor over-the-counter (OTC) versions of these drugs were available during the time period of our data. ${ }^{5}$ Historically, this class also included Seldane and Hismanal. We didn't include them in the data set primarily because we observe them very infrequently. However, we included a Hismanal withdrawal dummy in the estimation in order to control for the possibility that doctor preference on Claritin, Zyrtec and Allegra might have changed after the withdrawal of Hismanal. ${ }^{6}$ In total, we observe 2,545 patient-visits between July 1997 and 2001, which resulted in the prescription of one of the three allergy drugs. These patients correspond to 1,151 unique doctor identities, implying that on average we observe 2.21 patient-visits per doctor.

Non-sedating antihistamine is one of the most heavily advertised classes using direct-toconsumer channels. However, the use of DTCA differs somewhat among the three drugs, which allows us to identify the effects of advertising on the choice of prescription drugs. While Claritin is clearly the leader in DTCA expenditures in this class (see Figure 1), this does not appear to have helped increase or maintain its market share: Claritin's market share has declined since 1997 regardless of the large amount of DTCA (see Figure 2). This suggests that DTCA may not have a strong impact on the physician's prescription choice. Table 1 reports descriptive statistics.

\section{The Model}

If a physician maintains her authority to choose a drug, DTCA may encourage people "to seek medical help," but may not influence brand choice. On the other hand, if DTCA enables patients to "persuade" the physician to prescribe what they want, DTCA may have a positive effect on

\footnotetext{
${ }^{5}$ Claritin switched to the OTC market in 2002, and Clarinex entered the market also in 2002.

${ }^{6}$ Although Seldane was not officially withdrawn from the market until February 1998, FDA had proposed removing Seldane from the marketplace as early as January 1997 (FDA 1997). Since our analysis starts from July 1997, we believe the impact of Seldane withdrawal is minimal. Hismanal was introduced to the market in January 1998 and withdrawn on June 21, 1999. Hismanal withdrawal dummy equals one after July 1999.
} 
brand choice. To distinguish these arguments, we estimate demand for prescription drugs using a conditional logit model.

We assume that physician acts as an agent for the patient and chooses one drug out of the three alternatives (Claritin, Zyrtec, and Allegra) by incorporating both the patient's preference and his own professional knowledge and preference. Promotional activities can potentially affect the choice of prescription by altering the patient's and the physician's preference and knowledge. Specifically, we assume that physician $k$ chooses a drug for patient $i$ at time $t$, among $J$ alternatives $(J=3)$, which maximizes an objective function $V_{i j k t}$. We can interpret $V_{i j k t}$ as the utility of the physician who may internalize the patient's preference to some extent.

$$
\begin{aligned}
\max _{j \in J} V_{i j k t} & =\sum_{m=1}^{4}\left[\beta_{m} \cdot \sum_{x=0}^{t-t_{j 0}} \delta_{m}^{x} A_{j(t-x)}^{(m)}\right] \\
& +\beta_{X} X_{j t}+\beta_{P} P_{j t}+\beta_{j Y} Y_{i t}+\beta_{j H} H_{k t}+\beta_{j W} W_{t}+e_{k j t}+\epsilon_{i j k t} .
\end{aligned}
$$

Denoting $m$ as type of advertising, we distinguish four promotional expenditures in $A_{j t}$ : DTCA, detailing, professional journal advertising, and free samples. DTCA targets consumers, while the latter three are direct-to-physician promotions. Including all four allows us to separately examine the impact of different promotional devices available for pharmaceutical firms. Because the effect of advertising may last more than one month, for each type of advertising, we model the advertising stock as a sum of the flows from the month of drug entry $\left(t_{j 0}\right)$ to the month under study $(t)$ with a constant depreciation rate $\delta$ per month. We estimate a separate $\delta$ for each type of advertising. ${ }^{7}$

As for the other terms, $X_{j t}$ is a vector of product characteristics including both drug dummies and the age of the drug, $P_{j t}$ is the wholesale price, $Y_{i t}$ is a vector of patient $i$ 's attributes including insurance status (i.e. Medicare, Medicaid, private insurance and self-pay) and demographics (i.e. age, gender and race), $H_{k t}$ is a vector of physician $k$ 's specialty (i.e. family practice, internal medicine, and all others), and $W_{t}$ is a dummy set to one after Hismanal withdrawal. We allow the effects of $Y_{i t}, H_{k t}$, and $W_{t}$ to be drug specific, which effectively captures individual heterogeneity.

The error term consists of two parts: $e_{k j t}$ denotes physician $k$ 's unobserved preference for

\footnotetext{
${ }^{7}$ To construct advertising stock, we need data prior to July 1997. For DTCA, we have monthly DTCA expenditure data between January 1994 and June 1997. For professional advertising variables, we have annual data between 1994 and 1997 and monthly data after July 1997. To accommodate the seasonal nature of the disease and corresponding advertising expenditures, we allocate the annual data between 1994 and 1997 to each month using the observed pattern of advertising spending between 1998 and 2001. Specifically, for each advertising type, we compute the average expenditure share of each month between 1998-2001 and apply them to 1994-1997 data.
} 
$\operatorname{drug} j$, and $\epsilon_{i j k t}$ is the logit error independent across patients, doctors, and time. We treat $e_{k j t}$ as random effects that conform to a normal distribution with an unknown variance. ${ }^{8}$ In doing so, we capture the unobserved correlation among the patients that have seen the same doctor. ${ }^{9}$

To obtain parameter values, we write down the likelihood for each of the 2545 choice situations in our data (defined as patient-doctor-time), and maximize the overall likelihood by using the NLMIXED procedure in SAS. The procedure employs a dual quasi-Newton algorithm and adaptive Gaussian quadrature to allow for random effects (by physician identity) in the non-linear specification of conditional logit. Since there is a possibility for diminishing returns to advertising, we have also tried $\log \left(A_{j t}\right)$ or the quadratic term of $A_{j t}$ instead of linear $A_{j t}$. Since the main results never change, we only report those with linear $A_{j t}$.

There are some concerns that the advertising variables of our interest are endogenous in the sense that they could be correlated with aggregate demand shocks such as changes in demographics. This is particularly problematic in the studies that use aggregate sales data, where individual attributes are not observed. Fortunately, micro-level data we use allows us to include extensive interactions between patient/doctor characteristics and drug dummies, thus alleviating the problem. ${ }^{10}$ Moreover, advertising expenditures are usually determined three to four months ahead of time, so it is less likely that the simultaneity problem (or reverse causality) biases the estimates.

\section{Empirical Results}

We present the results in two tables: Table 2 reports the coefficients by advertising, individual characteristics, physician characteristics, and the timing of Hismanal withdrawal. Based on these estimates, Table 3 reports the marginal effect of increasing each type of advertising expenditure of drug $j$ on the probability of prescribing drug $j$.

Our main interest lies in the four types of promotional activities. As shown in Table 2,

\footnotetext{
${ }^{8}$ Precisely, there are two variance terms, one for Zyrtec and one for Allegra (Claritin is the comparison group).

${ }^{9}$ Aside from doctor clustering, one may also be concerned about unobserved correlations within the same drugmonth. To our knowledge, the econometric literature has not provided a universal solution for double clustering, and we believe doctor-clustering is more appropriate in this context.

${ }^{10}$ Some previous studies in this area (e.g., Berndt et al., 1995 and Iizuka and Jin, 2005) have used the instruments of the type "DTCA for the firm in unrelated classes." This strategy was difficult to implement in this case because the correlation between allergy advertising and the same firm's advertising in other classes is not strong. For example, Claritin accounts for most of Schering Plough's advertising budget and this leads to a very weak correlation between the ads expenditure of Claritin and Schering Plough's 18 other products.
} 
the coefficient for DTCA is not statistically different from zero, suggesting that, regardless of the massive DTCA campaign on allergy drugs, DTCA has no significant impact on physician's prescription choices. ${ }^{11}$ This contrasts with the results in Iizuka and Jin (2005) that DTCA increases visits to physicians substantially. Interestingly, the coefficients for detailing promotion and medical journal advertising are positive and weakly significant, suggesting that prescription choices are influenced by the promotional efforts targeted at doctors. These results suggest that consumer-directed and professional-directed advertising play quite different roles in promoting prescription drugs; while DTCA increases patients visits to doctors, professional advertising affects the doctor's prescription choice. The third type of professional advertising - free samples - appears to have little impact on prescription choice.

The marginal effects reported in Table 3 paint a more detailed picture: calculated at the sample average (weighted), the marginal effects suggest that increasing drug $j$ 's DTCA by $\$ 1$ million in a month has a positive but insignificant effect on the probability of prescribing drug $j$ in that month. This result is similar across all the three drugs. In comparison, one-milliondollar increase in Claritin detailing would enhance the probability of prescribing Claritin by $10.9 \%$ (with standard error 5.39\%). Similarly, one-million-dollar increase of journal advertising would lead to significantly more prescriptions in Claritin and Zyrtec, but not Allegra.

The estimated depreciation rates reported in Table 2 suggest that professional advertising lasts longer, while DTCA is short-lived. These depreciation rates are estimated precisely except that the coefficient on DTCA is not statistically different from zero and the DTCA depreciation reaches the lower bound of zero. These estimates suggest, for example, the effect of detailing reduces to $87.4 \%$ after one month and $66.8 \%$ after three months, but DTCA depreciates completely within a month. ${ }^{12}$

Since DTCA not only has a weaker impact in the current month, but also depreciates much faster in the following months, the overall effect of DTCA is substantially weaker than that of professional advertising. To give an example, suppose an average firm increases detailing promotion by $\$ 1$ million in a specific month (at the mean of all observed variables). This investment increases the cumulative stock of detailing promotion over the next 12 months by $\$ 6.36$ million. $^{13}$ If another firm tries to use DTCA to offset the business-stealing effect created by the first firm's detailing, this firm would have to increase DTCA by as much as $\$ 14.93$ million in the same month. ${ }^{14}$ This shows that the business-stealing effect of DTCA is much weaker than

\footnotetext{
${ }^{11}$ The result that the coefficient on DTCA is insignificant may have two interpretations: first, the true effect is indistinguishable from zero; second, our estimates are imprecise. Since the data have more variations in DTCA than in the other advertising variables, we suspect the first interpretation is more plausible.

${ }^{12}$ In a related research, Berndt et al. (2003) reports that, using aggregate data for antiulcer drugs, the effect of detailing reduces to $95 \%$ after one month.

${ }^{13} 1+0.874+0.874^{2}+. .+0.874^{11}=6.359$.

${ }^{14}$ We obtain this result as follows. First, if one spends $\$ 1$ million in DTCA in a specific month, the cumulative
} 
that of detailing. The same argument goes for professional journal advertising.

The other coefficients also provide insights into the demand for allergy drugs. The coefficient for price suggests that prescription choices are not sensitive to the wholesale price. As noted before, however, this may be because our price measure correlates poorly with the patient's out-of-pocket costs. Dummy variables corresponding to Allegra and Zyrtec are not different from zero, suggesting that the efficacy of the three drugs are similar. The interaction between Allegra and Hismanal withdrawal dummy is insignificant, suggesting that doctor preference between Allegra and Claritin did not change after the withdrawal. The same results hold for Zyrtec. Also, estimates suggest that women are less likely to receive Claritin relative to men, and older age increases the probability of receiving Allegra relative to Claritin and Zyrtec, in order. Relating to insurance status, Claritin is more popular among privately insured patients. Within Medicaid patients, Allegra is less preferred relative to Claritin and Zyrtec. ${ }^{15}$

\section{Discussion}

If we integrate the results shown above and the results from Iizuka and Jin (2005), DTCA seems effective in increasing aggregate demand per therapeutic class but does not affect doctor choice of prescription within a class. This suggests that the effect of DTCA is primarily market-expanding rather than business-stealing. Thus, DTCA may be viewed as a public good for all drugs in the same class. In this section, we provide supply-side evidence that supports this argument.

If DTCA is a public good, one may immediately ask why drug firms do not simply free ride on others' advertising efforts. Which companies, if any, have incentives to use DTCA given the nature of the advertising? To consider these questions, note that even if the public-good nature of DTCA does not allow an advertising company to reap the full benefits, the company may still find it worthwhile to advertise if the absolute effect of market-expansion is large enough. This suggests that companies with larger market shares are more likely to use DTCA, since they benefit more from the increased market size. Moreover, we would also expect that there is a cut-off point below which low-market share firms do not advertise at all. In fact, we can obtain a crude estimate on this threshold using the results from Iizuka and Jin (2005). In that paper, we reported that every $\$ 28$ DTCA after 1997 would generate one patient visit in the next 12 months. This implies that if one extra visit generates one prescription, consumer compliance rate is $60 \%$, and every filled prescription implies $\$ 80$ profits for the drug manufacturer, the stock of this DTCA over the next 12 months is still $\$ 1$ million. Using the coefficients reported in Table 2 , we can compute the necessary DTCA expenditures to offset detailing advertising as 6.359/1*0.4425/0.1885 = 14.93.

${ }^{15}$ However, we should be cautious because NAMCS collects information on the type of insurance that most likely covers the visit, not the resulting prescription. 
manufacturer will advertise as long as its market share is over $58.3 \% .^{16}$

To check these predictions, we look at all therapeutic classes included in NAMCS and examine which firms use DTCA more intensively. Here, we implicitly assume that the public good argument applies to all therapeutic classes, although our analysis up to this point focuses on antihistamines. The assumption is consistent with the existing evidence that DTCA has a much smaller or no impact on prescription choice relative to detailing (e.g., Rosenthal et al. (2003), Wosinska (2002)). We match the DTCA data for all prescription drugs obtained from CMR and NAMCS by drug name and year of visit. Since NAMCS is a national representative, we use the weight it assigns to each individual visit to compute the market share of each prescription drug in its drug class, where drug class is defined by the 4-digit National Drug Code as of 2000.

Table 3 tabulates yearly DTCA expenditure by whether a drug's market share within its class was $0-20 \%, 20-40 \%, 40-60 \%$, or $60+\%$ in the previous year. Using data covering between 1995 and 2000, the table shows that drugs with market shares $40 \%$ or higher in the previous year spent a lot more on DTCA per drug-year than those with smaller market shares. Put more crudely, the propensity of DTCA increases dramatically with market share: for drugs with $20 \%$ or less market shares in year t-1, only $3.7 \%$ advertise in year t. In contrast, for drugs with $60+\%$ market shares, $19 \%$ advertise. If restricted to the classes that ever used DTCA, a drug with a $60+\%$ market share on average accounts for $69 \%$ of the total DTCA expenditure in its class, while a drug with a $20-\%$ market share only contributes $4 \% .{ }^{17}$

This supports the argument that "larger" drugs benefit more from the market-expanding effects of DTCA, and therefore have more incentives to advertise than their "smaller" competitors within the same therapeutic class. Thus, the supply-side evidence is consistent with the demand side results that DTCA may be viewed as a public good in a therapeutic class.

\section{Conclusion}

This paper examined the effect of DTCA on doctor choice of prescription drugs. Using antihistamines as an example, we found that DTCA has little effect on the choice of brand despite the massive DTCA expenditure incurred in this class. In contrast, we found that direct-to-physician advertising (i.e., detailing and medical journal advertising) has a larger and long-lasting effect on prescription choice. These results, together with the market expanding results shown in Iizuka and Jin (2005), suggest that DTCA is effective in increasing the aggregate demand per

\footnotetext{
${ }^{16}$ That is, $28 /(80 * 0.6)=0.583$.

${ }^{17}$ All these patterns are robust if we estimate regression models, controlling for drug class fixed effects and common year dummies.
} 
therapeutic class but does not affect doctor choice of prescription within a class. Therefore, DTCA may be viewed as a public good for all drugs in the same class. Regarding the debate on the effect of DTCA, our results support the view of proponents that DTCA has little impact on the choice of prescription once the patient arrives at the physician office. We note, however, that welfare implications are far reaching, partly because our model does not consider the potential substitution between the antihistamines we examine and other alternatives such as non-drug treatments and over-the-counter medications.

\section{$7 \quad$ References}

Berndt, E.R., L. Bui, D.R. Reiley, and G.L. Urban [1995]: "Information, Marketing, and Pricing in the US Antiulcer Drug Market," American Economic Review, 85(2), pp. 100-105.

Berndt, E.R., R.S. Pindyck, and P. Azoulay [2003]: "Consumption Externalities and Diffusion in Pharmaceutical Markets: Antiulcer Drugs," Journal of Industrial Economics, 51(2), pp. 243-270.

Calfee, J., C. Winston, and R. Stempski [2002]: "Direct-to-Consumer Advertising and the Demand for Cholesterol-reducing Drugs" Journal of Law and Economics, pp. 673-690.

Cherry, D.K., C.W. Burt, D.A. Woodwell [2001]: "National Ambulatory Medical Care Survey: 1999 Summary" downloaded at www.cdc.gov.

Food and Drug Administration (FDA) [1997]:"FDA Proposes to Withdraw Seldane Approval" FDA Talk Paper T97-3, Jan. 13, 1997.

Hollon, M.F. [1999]: "Direct-to-Consumer Marketing of Prescription Drugs" Journal of American Medical Association, January 27, Vol 281, No. 4.

Holmer, A. [1999]: "Direct-to-Consumer Prescription Drug Advertising Builds Bridges Between Patients and Physicians" Journal of American Medical Association, January 27, Vol 281, No. 4.

Holmer, A. [2002]: "Direct-to-Consumer Advertising - Strengthening Our Health Care System" New England Journal of Medicine, February 14, Vol. 346, No. 7.

Iizuka, T. [2004]: "What Explains the Use of Direct-to-Consumer Advertising of Prescription Drugs?" Journal of Industrial Economics, Vol. 52, No. 3, pp. 349-379.

Iizuka, T. and G.Z. Jin [2005]: "The Effect of Prescription Drug Advertising on Doctor Visits" Journal of Economics and Management Strategy, Vol. 14, Issue 3, pp. 701-727.

Narayanan, S., R. Desiraju, and P.K. Chintagunta [2004]: "Return on Investment Implications for Pharmaceutical Promotional Exepnditures: The Role of Marketing-Mix Interactions," Journal of Marketing, Vol. 68, pp. 90-105. 
Rosenthal, M.B., E.R. Berndt, J.M. Donohue, and Richard G. Frank [2002]: "Promotion of Prescription Drugs to Consumers" New England Journal of Medicine, Feb. 14, Vol. 346, No. 7.

Rosenthal, M.B., E.R. Berndt, J.M. Donohue, A.M. Epstein and R.G. Frank [2003]: "Demand Effects of Recent Changes in Prescription Drug Promotion," in Frontiers in Health Policy Research, Vol. 6, D.M. Cutler and A.M. Garber, editors, MIT Press, pp. 1-26.

Wolfe, S.M. [2002]: "Direct-to-Consumer Advertising - Education or Emotion Promotion? " New England Journal of Medicine, February 14, Vol. 346, No. 7.

Wosinska, M. [2002]: "Just What the Patient Ordered? Direct-to- Consumer Advertising and The Demand for Pharmaceutical Products," unpublished manuscript. 


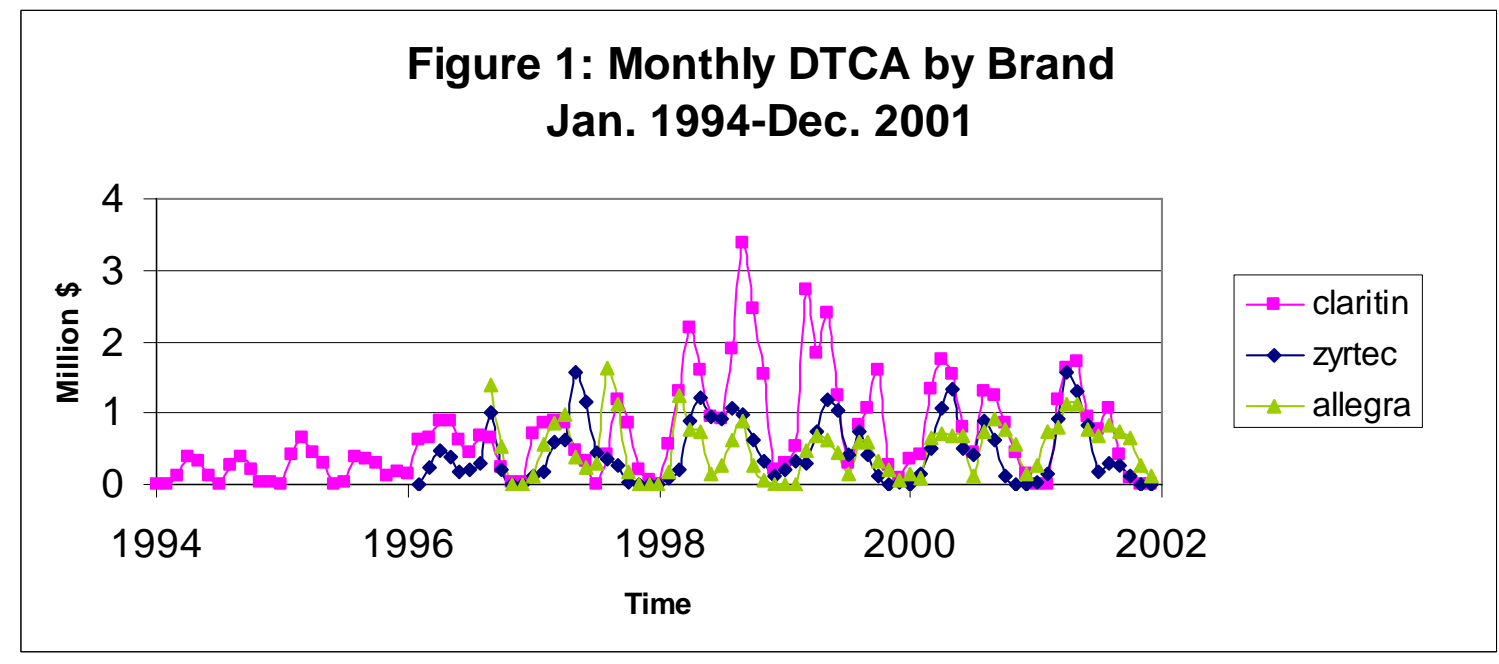

Figure 2: Market Share in the number of prescriptions of nonsedating antihistamines (source: NAMCS 1994-2001)

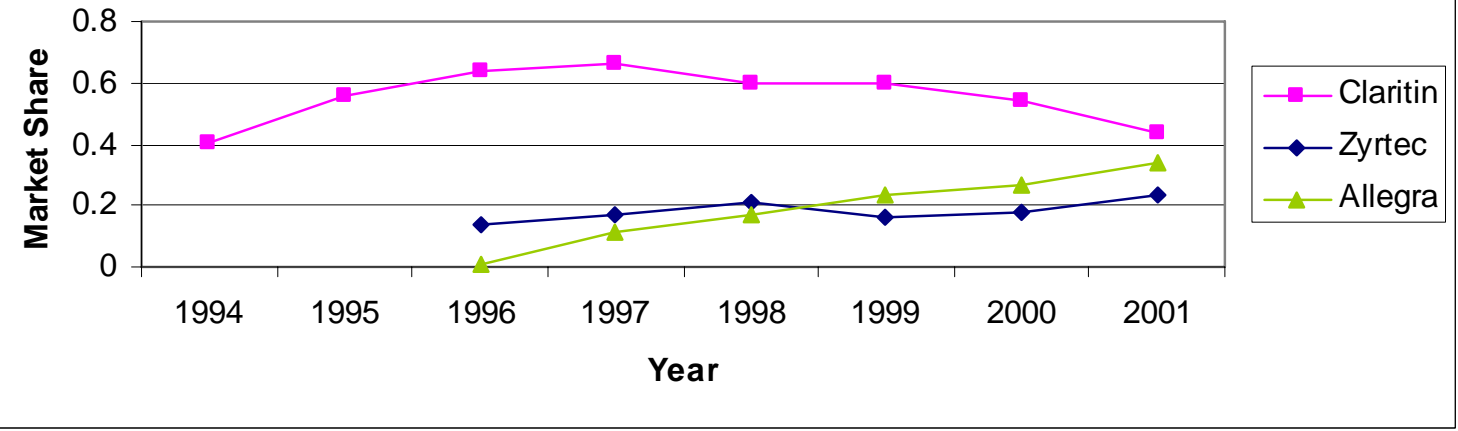

Note: Market shares of Claritin, Zyrtec and Allegra do not add up to one, because nonsedating antihistamines also include Seldane and Hismanal. Seldane entered the market in 1985, but was withdrawn in 1998. Hismanal was introduced in 1998 but withdrawn in 1999. 
Table 1: Summary Statistics

Drug Characteristics (Observation = drug-month, Jan. 1994 to Dec. 2001)

\begin{tabular}{|c|c|c|c|c|c|c|}
\hline \multirow{3}{*}{ Month of drug entry } & \multicolumn{2}{|c|}{ Claritin } & \multicolumn{2}{|c|}{ Zyrtec } & \multicolumn{2}{|c|}{ Allegra } \\
\hline & \multicolumn{2}{|c|}{ Apr. 1993} & \multicolumn{2}{|c|}{ Feb. 1996} & \multicolumn{2}{|c|}{ Sept. 1996} \\
\hline & Mean & Std. Dev. & Mean & Std. Dev. & Mean & Std. Dev. \\
\hline Monthly DTCA (million \$) since entry & 0.692 & $(0.689)$ & 0.459 & $(0.436)$ & 0.499 & $(0.391)$ \\
\hline Monthly Detailing (million \$) since entry & 0.608 & $(0.221)$ & 0.48 & $(0.114)$ & 0.567 & $(0.226)$ \\
\hline Monthly Prof. Jnl. Advertising (million \$) since entry & 0.035 & $(0.026)$ & 0.02 & $(0.019)$ & 0.054 & $(0.038)$ \\
\hline Monthly Free Samples (million \$) since entry & 1.189 & $(0.503)$ & 0.526 & $(0.193)$ & 0.717 & $(0.325)$ \\
\hline Wholesale price per patient-day (\$, Jul. 1997 to Dec. 2001 only) & 1.876 & $(0.063)$ & 1.429 & $(0.016)$ & 1.556 & $(0.075)$ \\
\hline
\end{tabular}

Patient and Doctor Characteristics (OBS = NAMCS patient record, Jul. 1997 to Dec. 2001)

\begin{tabular}{|l|cc|}
\hline & Mean & Std. Dev. \\
\hline Age & 41.129 & $(22.634)$ \\
Female & 0.602 & $(0.490)$ \\
White & 0.878 & $(0.328)$ \\
Private Insurance & 0.695 & $(0.460)$ \\
Medicare & 0.131 & $(0.337)$ \\
Medicaid & 0.061 & $(0.239)$ \\
Family doctor & 0.402 & $(0.490)$ \\
Internal Medicine & 0.204 & $(0.403)$ \\
Chosen prescription $=$ Claritin & 0.544 & $(0.498)$ \\
Chosen prescription $=$ Zyrtec & 0.200 & $(0.400)$ \\
Chosen prescription = Allegra & 0.256 & $(0.436)$ \\
\hline OBS & 2545 & \\
\hline
\end{tabular}

Data source: IMS, CMR and NAMCS. Standard deviation in parentheses. 
Table 2: Conditional Logit Coefficients (Dependent Variable $=$ Choice of Claritin, Zyrtec, Allegra)

\begin{tabular}{|c|c|c|c|}
\hline & Coeff. & Std. err. & \\
\hline Wholesale Price & 1.107 & 1.769 & \\
\hline Log (months since drug entry) & 1.136 & 2.217 & \\
\hline Stock of DTCA (million \$) & 0.189 & 0.128 & \\
\hline$\delta$ of DTCA & 0.000 & . & \\
\hline Stock of Detailing (million \$) & 0.443 & 0.255 & $*$ \\
\hline$\delta$ of Detailing & 0.874 & 0.076 & $* * *$ \\
\hline Stock of Prof. Journal Ad. (million \$) & 1.916 & 0.999 & $*$ \\
\hline$\delta$ of Prof. Journal Advertising & 0.977 & 0.040 & $* * *$ \\
\hline Stock of Free Sampling (million \$) & -0.054 & 0.136 & \\
\hline$\delta$ of Free Sampling & 0.997 & 0.033 & $* * *$ \\
\hline Dummy of Zyrtec & -0.087 & 3.496 & \\
\hline Dummy of Allegra & -3.158 & 4.683 & \\
\hline Allegra*After Hismanal Withdrawal & -0.597 & 0.441 & \\
\hline Zyrtec*After Hismanal Withdrawal & 0.255 & 0.447 & \\
\hline Allegra $*$ Female & 0.226 & 0.132 & $*$ \\
\hline Zyrtec * Female & 0.406 & 0.135 & $* * *$ \\
\hline Allegra * White & 0.507 & 0.207 & $* *$ \\
\hline Zyrtec * White & 0.206 & 0.209 & \\
\hline Allegra * Age & 0.026 & 0.004 & $* * *$ \\
\hline Zyrtec $*$ Age & -0.009 & 0.004 & $* * *$ \\
\hline Allegra $*$ Medicare & -0.839 & 0.287 & $* * *$ \\
\hline Zyrtec * Medicare & 0.369 & 0.300 & \\
\hline Allegra $*$ Medicaid & -1.209 & 0.370 & $* * *$ \\
\hline Zyrtec $*$ Medicaid & -0.052 & 0.320 & \\
\hline Allegra $*$ Private Insurance & -0.386 & 0.221 & $*$ \\
\hline Zyrtec * Private Insurance & -0.370 & 0.223 & $*$ \\
\hline Allegra $*$ Family doctor & 0.090 & 0.215 & \\
\hline Zyrtec $*$ Family doctor & -0.538 & 0.204 & $* *$ \\
\hline Allegra * Internal medcine doctor & 0.345 & 0.253 & \\
\hline Zyrtec * Internal medcine doctor & -0.287 & 0.249 & \\
\hline Variance of random effects by doctor - Allegra & 1.905 & 0.140 & $* * *$ \\
\hline Variance of random effects by doctor -- Zyrtec & 1.703 & 0.143 & $* * *$ \\
\hline OBS & 2545 & & \\
\hline Log likelihood per observation & -0.872 & & \\
\hline
\end{tabular}

Notes: The sample consists of NAMCS records on anti-histamine prescriptions, July 1997December 2001. ${ }^{* * *} \mathrm{p}<0.01,{ }^{* *} \mathrm{p}<0.05,{ }^{*} \mathrm{p}<0.1$, two-tail. 
Table 3: Marginal effects of Increasing \$1 million Advertising on Prescription Probability

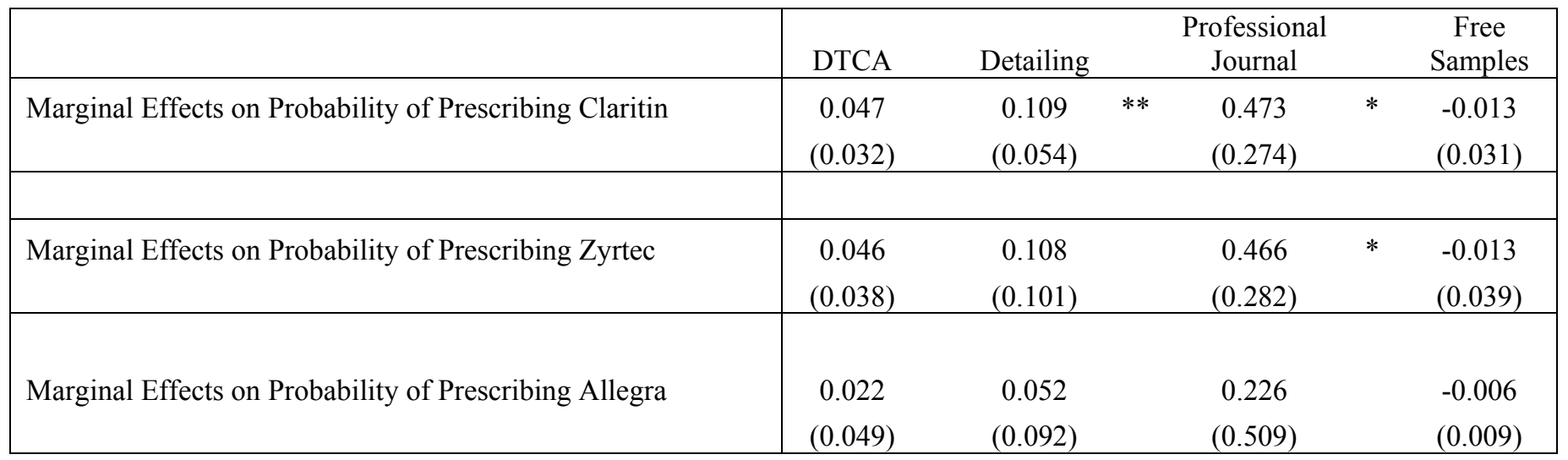

Notes: The number reported in row $\mathrm{r}$ column $\mathrm{c}$ is the effect of increasing $\$ 1$ million advertising of type $\mathrm{c}$ of drug $\mathrm{r}$ on the probability of prescribing drug $r$ in the advertised month. All effects are estimated at the sample average (weighted). Standard error in parentheses. ${ }^{* *} \mathrm{p}<0.05,{ }^{*} \mathrm{p}<0.1$, two-tail. 
Table 4: Relating DTCA of the current year to market shares as of the previous year

Observation $=$ drug-year

Sample Period $=$ NAMCS 1995 to 2000

\begin{tabular}{|c|c|c|c|c|c|}
\hline \multirow[b]{2}{*}{$\begin{array}{c}\text { Market Share in \# of drug mentions } \\
\text { (year t-1) }\end{array}$} & \multicolumn{3}{|c|}{ Full Sample } & \multicolumn{2}{|c|}{ Advertising Classes Only } \\
\hline & OBS & $\begin{array}{c}\text { DTC } \\
\text { Expenditure } \\
(\$ 1000) \\
(\text { year } \mathrm{t}) \\
\end{array}$ & $\begin{array}{c}\text { DTC at all? } \\
(\text { year } \mathrm{t})\end{array}$ & OBS & $\begin{array}{c}\text { DTC Share } \\
\text { Within Class } \\
(\text { year } t)\end{array}$ \\
\hline $0-20 \%$ & 5702 & 469.67 & 0.04 & 2518 & 0.04 \\
\hline $20-40 \%$ & 484 & 2254.01 & 0.12 & 164 & 0.2 \\
\hline $40-60 \%$ & 166 & 5333.02 & 0.16 & 49 & 0.32 \\
\hline $60+\%$ & 148 & 4888.44 & 0.19 & 37 & 0.69 \\
\hline
\end{tabular}

Data source: all prescription drugs mentioned in NAMCS 1995-2000. Market share is calculated by the number of mentions for drug $\mathrm{j}$ in NAMCS of year t-1, divided by the total number of drug mentions within the same drug class in NAMCS of year t-1, all weighted. "DTC at all" refers to a dummy variable equal to one if there is any DTC advertising expenditure for drug $\mathrm{j}$ in year $\mathrm{t}$. An observation of drug-year is included in the subsample of "Advertising Classes Only" if there is any DTC advertising expenditure in the corresponding drug class in year $t$. 